\title{
MIGRAINE: A POSSIBLE CAUSE FOR COGNITIVE DECLINE
}

\section{POORNIMA KN ${ }^{1 *}$, KARTHICK N ${ }^{1}$, KANIMOZHI SADASIVAM ${ }^{1}$, MEERA SHIVASEKAR ${ }^{2}$, SUNDAR SHANMUGAM ${ }^{3}$, BALAKRISHNAN D ${ }^{4}$, SARAVANAN A}

${ }^{1}$ Department of Physiology, SRM Medical College and Research Centre, Chennai, Tamil Nadu, India. ${ }^{2}$ Department of Biochemistry, SRM Medical College and Research Centre, Chennai, Tamil Nadu, India. ${ }^{3}$ Department of Neurology, SRM Medical College and Research Centre, Chennai, Tamil Nadu, India. ${ }^{4}$ Department of Speech Language Pathology, SRM Medical College and Research Centre, Chennai, Tamil Nadu, India. Email: poornimakarthic@gmail.com

Received: 01 February 2017, Revised and Accepted: 20 February 2017

ABSTRACT

Objectives: Migraine is the second most common type of headache and seventh most disabling disease worldwide. In general, obesity is often related to headache disorders in several clinical and epidemiologic studies. Obese migraine patients may have an increased attack frequency due to the increase in inflammatory response. Cognitive decline is present in several migraine patients. However, some researchers differ. Body mass index (BMI) is also seen to have a role in migraine. This study has been done (i) to define whether cognitive decline is present in a significant degree in migraine patients and also (ii) to test whether an association exists between migraine and BMI.

Methods: The study protocol was approved by the ethical committee of SRM Medical College Hospital and Research Centre. The study group consisted of 30 migraine patients and 30 healthy controls aged between 18 and 40 years of age. Informed consent was obtained from all the participants. The diagnosis of migraine was made using the criteria of the $2^{\text {nd }}$ edition of International Headache Classification. Patients affected by diabetes mellitus, hypertension, allergy, inflammation, infection, or immune disorders were excluded from the study to avoid confounding etiology. Height and weight of the subjects were taken to calculate the BMI. Cognitive tests such as Stroop interference trial and trial-making tests (A and B) were done to evaluate working memory, mental flexibility, and attention.

Results: Compared to controls, cases took more time for performing Stroop color card test $(106.40 \pm 15.87$ seconds vs. $132.17 \pm 7.027$ seconds, $\mathrm{p}<0.001)$ and trial-making pattern B $(54.77 \pm 8.169$ seconds vs. $56.23 \pm 23.457$ seconds, $\mathrm{p}=0.004)$. Among the migraine subjects, obese individuals had an increased frequency of migraine attack per month (correlation coefficient $r=0.797$ ).

Conclusion: In this study, we have found a linear increase in the frequency of migraine in persons with higher BMI. Moreover, migraine subjects had a decline in cognitive function in our study, and it is found to be statistically significant. Identifying cognitive decline early can prevent major consequences in day-to-day activities of migraine patients. Since there is an increased frequency of migraine with increase in BMI, obese migraine subjects can be recommended to do regular exercises.

Keywords: Migraine, Cognition, Stroop test, Obesity.

(C) 2017 The Authors. Published by Innovare Academic Sciences Pvt Ltd. This is an open access article under the CC BY license (http://creativecommons. org/licenses/by/4. 0/) DOI: http://dx.doi.org/10.22159/ajpcr.2017.v10i5.17436

\section{INTRODUCTION}

Migraine is a common neurological disorder, and it is responsible for almost $3 \%$ of disease burden according to the Global Burden of Disease Study of 2010 [1]. It is a markedly disabling condition and exerts a significant burden on the sufferer in terms of pain, suffering, and impaired quality of life [2]. Obesity and migraine are the two common health problems which at times may interlink [3]. Previous studies suggest an association between migraine and obesity. Obesity may affect the frequency of migraine attacks per month and cause crippling headaches $[4,5]$. The mechanism behind obesity and migraine remains unclear. Growing evidence suggests that there could be an increase in inflammatory response mainly due to the release of proinflammatory cytokines in obesity which triggers the migraine attack [6]. Neurogenic inflammation causes release of tumor necrosis factor-alpha (TNF- $\alpha$ ) and interleukin-6 (IL-6) [7,8]. The levels of these cytokines were found to be increased in migraine [9]. Elevated levels of TNF- $\alpha$ and IL-6 may have an adverse effect on synaptic plasticity and cognition. Migraine and obesity are said to be associated with increased TNF- $\alpha$ and IL-6. Further increased frequency of migraine attack in obesity may tend to accelerate cognitive decline. As the data from previous studies in determining cognition among migraine patients are scarce, we intended to do this study on cognition in migraine and its association with obesity.

\section{METHODS}

After obtaining the Institutional Ethical Clearance, an observational case-control study was conducted in a private medical hospital. The study duration was about 9 months, conducted from September 2015 to June 2016. Thirty migraine subjects who attended neurology outpatient department and 30 individuals aged between 18 and 40 years were recruited in this study. Informed consent was obtained from all the participants. Diagnosis of migraine was made using the criteria of the $2^{\text {nd }}$ edition of International Headache Classification [10]. Patients affected by diabetes mellitus, hypertension, allergy, inflammation, infection, or immune disorders were excluded from the study. Height and weight of the subjects were taken to calculate the body mass index (BMI).

Cognitive tests such as Stroop interference trial and trial-making tests (A and B) were done to evaluate working memory, mental flexibility, and attention. Stroop interference trial comprises of three cards A, B, and C. Card A (color card) contains 100 patches of three different colors, Card B (word card) contains names of the colors printed in black and white, and Card C (color-word card) contains the name of the color printed in a conflicting color ink (e.g., red color may be printed in blue or green color ink). The subject's (S's) task on card A is simply to utter the names of the colored patches as rapidly as possible, scanning 
the rows left to right. On card $\mathrm{B}$, the $\mathrm{S}$ reads aloud the color names as rapidly as possible. On card $\mathrm{C}$, the $\mathrm{S}$ is required to name the colors of the inks while ignoring the conflicting printed color names. The S's basic score on each card is the total time (in seconds) he/she takes to utter the 100 names [11].

Trial-making pattern A is a chart consists of series of numerical arranged in a jumbled manner. The subject has to join the numbers in ascending order without lifting the pen as soon as possible. Trialmaking pattern B is a chart consists numerical and alphabets arranged in a jumbled manner. The subject has to join the numbers and alphabets in a systematic order, for example, subject has to join 1 to A followed by 2 and then to $\mathrm{B}$ in a sequential order. The time taken to complete the task was noted in seconds.

\section{RESULTS}

In our study, we have found that there was no significant difference in age and BMI between controls and cases (Table 1). We have also found that the time taken to complete the cognitive tasks by migraineurs was much longer than the controls in trial-making pattern $B(p=0.004)$ and Stroop color card test $(\mathrm{p}=0.000)$ and they are statistically significant (Table 2). We have found a positive correlation between BMI and migraine attack frequency per month ( $\mathrm{r}=0.797)$. As the BMI increases, the attack frequency per month also increases (Fig. 1)

Fig. 1 shows the correlation between BMI and frequency of migraine among migraineurs.

Fig. 2 shows the schematic illustration of the possible inflammatory pathway exists in migraine and obesity on cognition. Previous studies have shown that the levels of TNF- $\alpha$ and IL- 6 were found to be increased in migraine patients. Obesity, a mediator of inflammation, also increases the levels of TNF- $\alpha$ and IL- 6 which in turn increases the frequency of migraine. TNF- $\alpha$ and IL- 6 play a significant role in cognition. Increase in these two proinflammatory cytokines has a deleterious effect on cognition.

\section{DISCUSSION}

Overweight and obesity are defined as abnormal or excessive fat accumulation that may impair health. Overweight and obesity are the fifth leading risk for global deaths. At least 2.8 million adults die each year as a result of being overweight or obese [12]. Past studies have shown that the frequency of migraine increases with increase in BMI [13-15]. In our study also, we have found that there is linear increase in the attack frequency as BMI increases, and it is found to be statistically significant (Fig. 1). The mechanism behind this correlation is very complex. Migraine, as such a disorder of inflammation along with obesity, imposes an increased risk of future complications by releasing inflammatory cytokines [16,17]. Adipocytes releases increased amount of proinflammatory cytokines such as TNF- $\alpha$, IL-6, and IL-1 in migraineurs when compared to healthy controls [18]. In obesity too, these inflammatory cytokines are increased which causes constant mild inflammation that triggers migraine-related inflammatory reactions. This increases the frequency and severity of migraine [16].

Interestingly, TNF- $\alpha$ and IL- 6 have a beneficial role in memory and cognition when they are within the normal limit [19]. Increased levels of TNF- $\alpha$ and IL- 6 have a deleterious effect on cognition [20,21]. Growing evidence suggests that the cytokines IL- 6 and TNF- $\alpha$ are involved in the molecular and cellular mechanism of complex cognitive processes $[22,23]$. They play a major role in synaptic plasticity, longterm potentiation, neurogenesis, and memory consolidation. IL- 6 and TNF- $\alpha$ exert multiple physiological functions within the CNS, which are both neuroprotective and neurodegenerative [24]. Increased levels of IL-6 cause neural stem cell dysfunction and an associated decline in learning and memory [25]. Cognitive impairment has also been demonstrated in transgenic mice overexpressing TNF- $\alpha$ [26]. It is due
Table 1: Demographic profile of controls and migraine patients (cases)

\begin{tabular}{llll}
\hline Parameters & \multicolumn{2}{l}{ Mean \pm SD } & p value \\
\cline { 2 - 3 } & Control & Case & \\
\hline Age $($ years $)$ & $29.30 \pm 4.85$ & $28.40 \pm 5.29$ & 0.493 \\
BMI $\left(\mathrm{kg} / \mathrm{m}^{2}\right)$ & $26.64 \pm 3.32$ & $26.40 \pm 3.54$ & 0.632 \\
\hline
\end{tabular}

Results are expressed as mean \pm SD of 30 in each group. SD: Standard deviation, BMI: Body mass index

Table 2: Cognitive tests results between controls and migraine patients (cases)

\begin{tabular}{lll}
\hline Parameters & Control (seconds) & Case (seconds) \\
\hline Trial-making pattern A & $31.53 \pm 13.31$ & $31.77 \pm 14.46$ \\
Trial-making pattern B & $54.77 \pm 8.169$ & $56.23 \pm 23.457^{* * *}$ \\
Stroop (B/W) & $38.2 \pm 3.9$ & $50.53 \pm 4.98$ \\
Stroop color & $66.9 \pm 7.8$ & $70.6 \pm 7.1$ \\
Stroop color-word & $106.40 \pm 15.87$ & $132.17 \pm 7.027^{* * *}$ \\
card test & & \\
\hline
\end{tabular}

Results are expressed as mean \pm SD of 30 in each group; ${ }^{* * *} \mathrm{p}<0.001$.

SD: Standard deviation

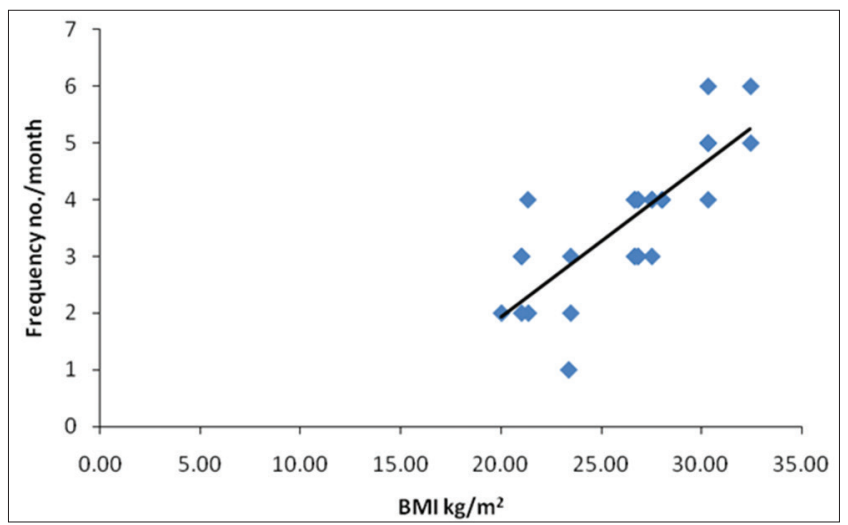

Fig. 1: Correlation between body mass index and frequency of migraine among migraineurs

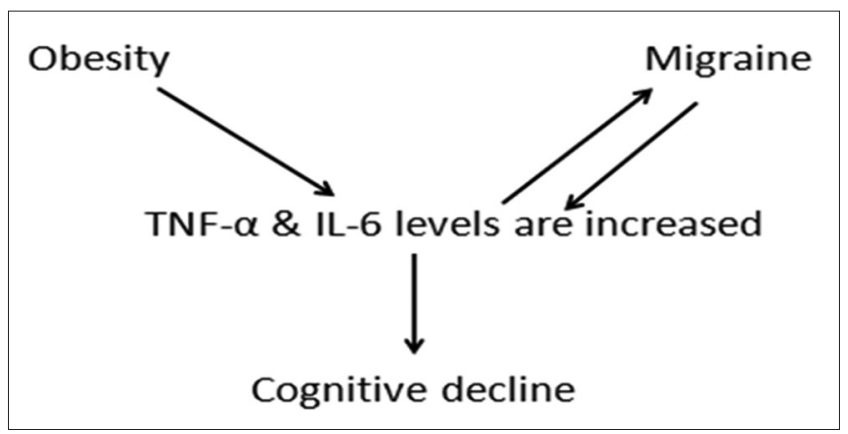

Fig. 2: Mechanism of inflammatory pathway

to the changes in synaptic plasticity and impairment of long-term potentiation which causes neurodegeneration [27].

We have found that there is decline in cognition in migraineurs when compared with controls especially in executive functions and mental flexibility, and it is statistically significant (Table 2). This could be due to the release of inflammatory cytokines which decreases cognition. However, we did not find any significant difference in cognition among normal weight and obese migraine patients. From this, we can conclude that even though obesity increases the frequency of migraine, it does 
not have a direct effect on cognition in migraine patients. However, repeated attacks of migraine may predispose the individual to early cognitive decline. Hence, obesity seems to be an independent risk for migraine and migraine-related cognitive decline. This is one of the very few studies done in young migraine patients, that is, during their most productive years.

\section{CONCLUSION}

Early identification and prevention of cognitive decline in migraineurs will prevent major difficulty in day-to-day activities of the migraine subjects. There is an urgent need to emphasis on the maintenance of normal BMI to prevent increased attack frequency which in turn further declines the cognition much early in life.

\section{REFERENCES}

1. Baldacci F, Lucchesi C, Cafalli M, Poletti M, Ulivi M, Vedovello M, et al. Migraine features in migraineurs with and without anxietydepression symptoms: A hospital-based study. Clin Neurol Neurosurg 2015;132:74-8.

2. Timothy SY, Kwanashie HO, Nyandaiti YW, Watila M, Mava Y, Sadiq GU, et al. Impact of weather conditions on migraine headache in North-Eastern Nigeria. Int J Pharm Pharm Sci 2011;3 Suppl 3:133-6.

3. Yang M, Yang J, Zeng F, Liu P, Lai Z, Deng S, et al. Electroacupuncture stimulation at sub-specific acupoint and non-acupoint induced distinct brain glucose metabolism change in migraineurs: A PET-CT study. J Transl Med 2014;12(1):351.

4. Guldiken B, Guldiken S, Demir M, Turgut N, Tugrul A. Low leptin levels in migraine: A case control study. Headache 2008;48(7):1103-7.

5. He-min Z, Guo-Rong B, Qiu H, Xiang L, Suli L. Changes in plasma PPARs levels in migraine patients. Med Sci Monit 2015;21:735-9.

6. Peterlin BL. The role of the adipocytokines adiponectin and leptin in migraine. J Am Osteopath Assoc 2009;109(6):314-7.

7. Paganelli R, Di Iorio A, Patricelli L, Ripani F, Sparvieri E, Faricelli R, et al. Proinflammatory cytokines in sera of elderly patients with dementia: Levels in vascular injury are higher than those of mild-moderate Alzheimer's disease patients. Exp Gerontol 2002;37(2-3):257-63.

8. Fillit H, Ding WH, Buee L, Kalman J, Altstiel L, Lawlor B, et al. Elevated circulating tumor necrosis factor levels in Alzheimer's disease. Neurosci Lett 1991;129(2):318-20.

9. Perini F, D'Andrea G, Galloni E, Pignatelli F, Billo G, Alba S, et al. Plasma cytokine levels in migraineurs and controls. Headache 2005;45(7):926-31.

10. Headache Classification Committee of the International Headache Society. The International Classification of Headache Disorders: $2^{\text {nd }}$ edition. Cephalalgia 2004;Suppl 1:1-160.
11. Thurstone LL, Mellinger JJ. The Stroop Test, Report No. 3. Chapel Hill, NC: Psychometric Laboratory; 1953.

12. Durga GL, Jhansi C, Ram VR, Nadendla RR. An epidemiologiacal survey on prevalence of obesity and diseases burden in common public. Int J Pharm Pharm Sci 2014;6 Suppl 2:320-2.

13. Winter AC, Berger K, Buring JE, Kurth T. Body mass index, migraine, migraine frequency and migraine features in women. Cephalalgia 2009;29(2):269-78.

14. Winter AC, Wang L, Buring JE, Sesso HD, Kurth T. Migraine, weight gain and the risk of becoming overweight and obese: A prospective cohort study. Cephalalgia 2012;32(13):963-71.

15. Ornello R, Ripa P, Pistoia F, Degan D, Tiseo C, Carolei A, et al. Migraine and body mass index categories: A systematic review and meta-analysis of observational studies. J Headache Pain 2015;16:27.

16. Bigal ME, Lipton RB, Holland PR, Goadsby PJ. Obesity, migraine, and chronic migraine: Possible mechanisms of interaction. Neurology 2007;68(21):1851-61.

17. Bond DS, Roth J, Nash JM, Wing RR. Migraine and obesity: Epidemiology, possible mechanisms and the potential role of weight loss treatment. Obes Rev 2011;12(5):e362-71.

18. Sarchielli P, Alberti A, Baldi A, Coppola F, Rossi C, Pierguidi L, et al. Proinflammatory cytokines, adhesion molecules, and lymphocyte integrin expression in the internal jugular blood of migraine patients without aura assessed ictally. Headache 2006;46(2):200-7

19. Beattie EC, Stellwagen D, Morishita W, Bresnahan JC, Ha BK, Von Zastrow M, et al. Control of synaptic strength by glial TNF alpha. Science 2002;295(5563):2282-5.

20. Alvarez A, Cacabelos R, Sanpedro C, García-Fantini M, Aleixandre M. Serum TNF-alpha levels are increased and correlate negatively with free IGF-I in Alzheimer disease. Neurobiol Aging 2007;28:533-6.

21. Dik MG, Jonker C, Hack CE, Smit JH, Comijs HC, Eikelenboom P. Serum inflammatory proteins and cognitive decline in older persons. Neurology 2005;64:1371-7.

22. Pickering M, O'Connor JJ. Pro-inflammatory cytokines and their effects in the dentate gyrus. Prog Brain Res 2007;163:339-54.

23. Viviani B, Gardoni F, Marinovich M. Cytokines and neuronal ion channels in health and disease. Int Rev Neurobiol 2007;82:247-63.

24. Gemma C, Catlow B, Cole M, Hudson C, Samec A, Shah N, et al. Early inhibition of TNFalpha increases 6-hydroxydopamine-induced striatal degeneration. Brain Res 2007;1147:240-7.

25. Godbout JP, Johnson RW. Interleukin-6 in the aging brain. J Neuroimmunol 2004;147(1-2):141-4.

26. Fiore M, Angelucci F, Alleva E, Branchi I, Probert L, Aloe L. Learning performances, brain NGF distribution and NPY levels in transgenic mice expressing TNF-alpha. Behav Brain Res 2000;112(1-2):165-75.

27. Capsoni S, Cattaneo A. On the molecular basis linking Nerve Growth Factor (NGF) to Alzheimer's disease. Cell Mol Neurobiol 2006;26(4-6):619-33. 